\title{
Vesicouterine fistula presenting with urinary incontinence 30 years after primary Cesarean: Case report and review of the literature
}

\author{
Funda Gungor Ugurlucan, MD; Ercan Bastu, MD; Baris Bakir, MD; Onay Yalcin, MD \\ Istanbul University Istanbul School of Medicine Department of Obstetrics and Gynecology, Turkey
}

Cite as: Can Urol Assoc J 2014;8(1-2):e48-50. http://dx.doi.org/10.5489/cuaj.1225

Published online January 14, 2014.

\section{Abstract}

A vesicouterine fistula is an abnormal communication between the bladder and the uterus. The most common cause is lower segment Cesarean section. Conservative treatment may be applied in some cases, but surgery is the definitive treatment. We present a 55-year-old woman with vesicouterine fistula after primary Cesarean section; she presented with urinary incontinence 30 years later. Methylene blue dye test was performed and drainage of urine dyed with methylene blue through the uterine cervix was observed. Diagnosis was confirmed with magnetic resonance imaging. Total abdominal hysterectomy and bilateral oophorectomy was performed and the bladder wall was sutured in a double layer with $2 / 0$ polyglycolic suture. No complications developed and the patient did not suffer from any urinary incontinence afterwards. Vesicouterine fistula should be suspected in cases presenting with urinary incontinence even years after Cesarean section; diagnostic tests and, if necessary, appropriate surgery should be performed.

\section{Introduction}

A vesicouterine fistula is an abnormal communication between the bladder and the uterus. The first case was reported by Knipe and colleagues in $1908 .{ }^{1}$ Vesicouterine fistulas account for $1 \%$ to $4 \%$ of urogenital fistulas. ${ }^{2}$ The most common cause of a vesicouterine fistula is lower segment Cesarean section. Spontaneous vesicouterine fistula has been reported after vaginal delivery following a previous Cesarean section. ${ }^{3}$ Main presenting symptoms are urinary incontinence, amenorrhea, and menouria. Conservative treatment may be applied in some cases, but surgery is the definitive treatment. Transabdominal, laparoscopic or robotic methods can be used. We present a case with vesicouterine fistula after primary Cesarean section; the patient presented with urinary incontinence 30 years later.

\section{Case report}

A 55-year old G1P1 woman presented with urinary incontinence. Her medical history was unremarkable except for a lower segment Cesarean section due to transverse lie 30 years ago. Gynecologic examination was unremarkable with a negative cough test. Methylene blue dye test was performed and drainage of urine dyed with methylene blue through the uterine cervix was observed by speculum. Transvaginal sonography revealed a normal sized uterus and ovaries. Magnetic resonance imaging with contrast showed a fistula tract between the posterior wall of the bladder and the anterior wall of the uterus at the level of the previous Cesarean scar (Fig. 1). A vesicouterine fistula was diagnosed. Treatment options and pros and cons of the operative procedures, including laparotomy, robotic, and laparoscopic surgery, were discussed with the patient, but she preferred and gave consent for laparotomy.

The patient was operated through a Pfannenstiel incision. The patient underwent a total abdominal hysterectomy and bilateral oophorectomy. When we created the bladder flap, we entered the bladder and the fistula tract was exposed (Fig. 2). The bladder was dissected away from the uterus and the fistula tract on the bladder wall was excised. The bladder wall was sutured in a double layer with $2 / 0$ polyglycolic suture after visualization of the ureteral orifices. The vagina was sutured with a single layer continuous 0 polyglycolic suture. At completion of the bladder wall repair, the bladder was filled with sterile saline, which was instilled through the 18-Fr Foley catheter via the urethra. There was no leakage. A drain was inserted in the abdominal cavity, which was removed on postoperative day 2 . The postoperative course 


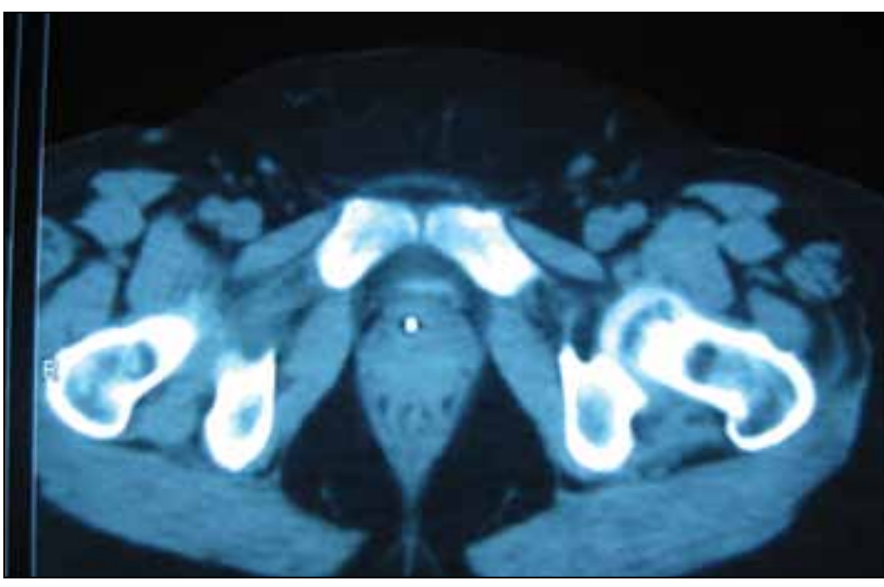

Fig. 1. Magnetic resonance imaging with contrast filled through the bladder showing contrast in the lower uterine segment at the level of the previous Cesarean scar.

was uneventful and the Foley catheter was withdrawn on the fifth postoperative day. The patient did not suffer from any urinary incontinence afterwards.

\section{Discussion}

The prevalence of vesicouterine fistula has been reported as $1 \%$ to $4 \%$ in most series, but is increasing due to an increase in Cesarean sections; ${ }^{4,5} 83 \%$ of the cases are attributed to Cesarean section. ${ }^{6}$ The possible mechanisms underlying the development of vesicouterine fistula include inadequate mobilization of the bladder flap, sutures passing through the bladder wall, unrecognized trauma to the bladder wall, excessive devascularization of the bladder during dissection, and cauterization. ${ }^{7,8}$ The risk increases in repeat Cesarean sections because of scarring and the presence of dense adhesions obscuring dissection in the right planes. ${ }^{9}$

In 1957, Youssef described the classic triad of amenorrhea, and cyclic hematuria (menouria) in the absence of urinary incontinence, which is characteristic of vesicouterine fistula, as Youssef's syndrome. ${ }^{10}$ Recurrent urinary tract infections, secondary infertility, and first trimester abortions may be observed. ${ }^{7}$ It is rare that urinary incontinence is the only symptom. Interestingly, our patient presented with urinary incontinence 30 years after the Cesarean section. The reason for this delay in seeking treatment might be that urinary incontinence symptoms did not have an adverse effect on her quality of life. Actually, most patients with vesicouterine fistula are continent. ${ }^{10}$

A diagnosis can be made during gynecologic examination or methylene blue dye test by observing drainage of urine through the uterine cervix by speculum. Intravenous pyelography, cystoscopy, hysterosalpingography, and transvaginal sonography have also been used for diagnosis. ${ }^{11}$ MRI has now become the first choice in the investigation of fistulas. ${ }^{12,13}$

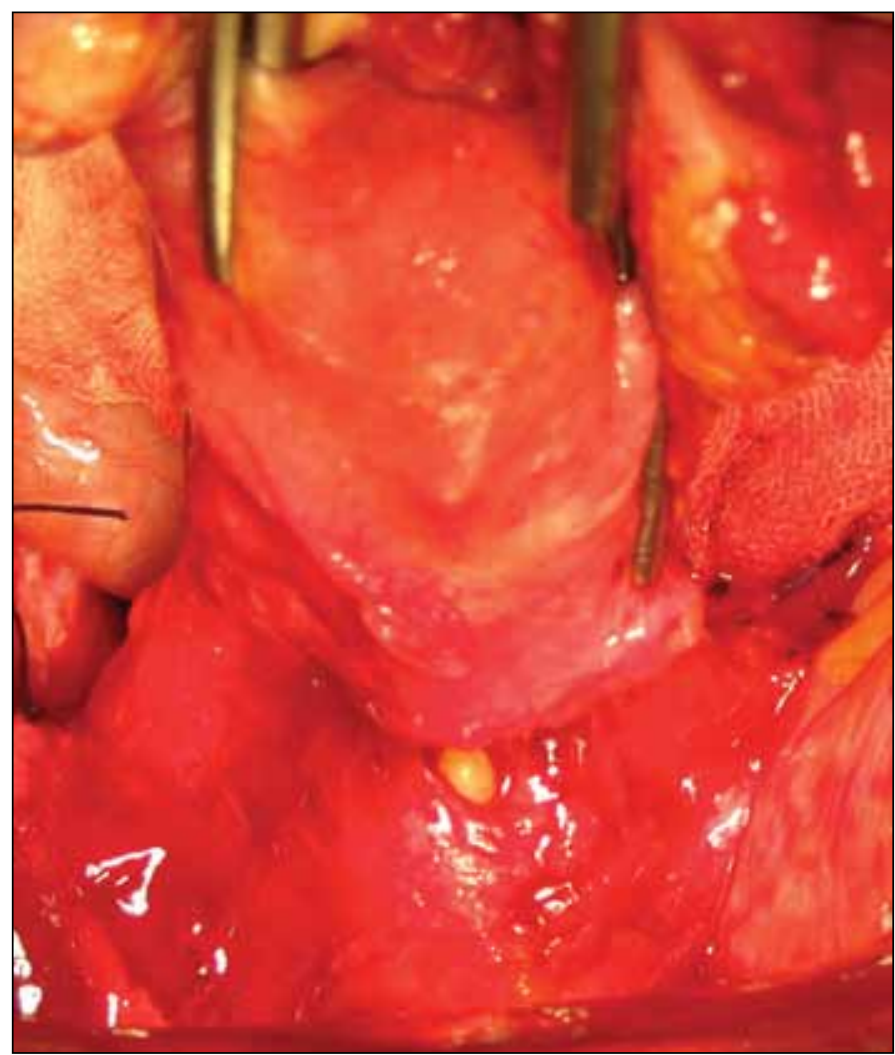

Fig. 2. The Foley catheter is observed through the bladder wall defect created during dissection of the bladder wall and the fistula tract from the uterus.

Treatment methods include expectant management with long-term bladder catheterization, medical treatment, and surgery. Spontaneous closure of vesicouterine fistula has been reported. ${ }^{14}$ Medical treatment involves induction of amenorrhea to aid in fistula healing. ${ }^{15}$ Oral contraceptives, progestational agents, and gonadotropin releasing hormone analogs have been used to induce amenorrhea. ${ }^{6}$ Surgery is the definitive method of treatment. It can be performed transabdominally, endoscopically, and robotically. The transvaginal approach is not preferred because of the higher location and complexity of the fistulas.

Transabdominal repair can be performed by extraperitoneal or retrovesical ( $\mathrm{O}^{\prime}$ Connor) technique. ${ }^{16}$ Disadvantages of the transabdominal route are increased morbidity, long hospital stay, and increased blood loss; these can be overcome by using the endoscopic and robotic approaches. ${ }^{11}$ For the laparoscopic approach, the surgeon should be skilled in fistulous tract dissection and intracorporeal suturing. Robotic-assisted surgery overcomes some of the difficulties related to the laparoscopic approach by better imaging and ease of intracorporeal suturing. ${ }^{17}$

During surgery, if the uterus is to be preserved, the bladder is mobilized off the anterior lower uterine segment and the fistula tract is excised. Wide excision is not necessary; excision of only the edges is enough to preserve the vascularity 
Ugurlucan et al.

of the tissues and make the repair easier. Delayed absorbable sutures are preferred for repair of both the uterus and the bladder. An omental flap may be interposed between the uterus and the bladder to prevent recurrence. Our patient did not want her uterus to be preserved. Therefore, hysterectomy was performed and the fistula tract remaining in the bladder wall was trimmed and the bladder wall was sutured in double layers with delayed absorbable sutures. When the bladder wall repair was completed, the bladder was filled to assess the integrity of the closure with sterile saline, which was instilled through the 18-Fr Foley catheter via the urethra. We did not detect any leakage; if a leakage would have occurred, then additional sutures would have been necessary. If the uterus would have been preserved, then a Foley catheter would have been left in place for 2 weeks. ${ }^{11}$ In our case, we kept the Foley catheter for 5 days to help with the healing of the cystotomy.

\section{Conclusion}

We present a case of vesicouterine fistula presenting 30 years after primary Cesarean section. Our case is unique; the only presenting symptom was urinary incontinence with no other related symptoms. Vesicouterine fistula should be suspected in patients with urinary incontinence after Cesarean section; diagnostic tests and, if necessary, appropriate surgery should be performed.

Competing interests: Dr. Ugurlucan, Dr. Bastu, Dr. Bakir and Dr. Yalcin all declare no competing financial or personal interests.

This paper has been peer-reviewed.

\section{References}

1. Knipe WHW. Vesico-uterine fistula. Am J Obstet Gynecol 1908:57:211-7.

2. Noabachie GC, Nioku 0. Vesico-uterine fistula. Br J Urol 1985;57:438-9. httpp://dx.doi.org/10.1111/ j.1464-410X.1985.tb06305.x

3. Dodero D, Corticelli A, Caporale E, et al. Endometriosis arises from implant of endometriotic cells outside the uterus: a report of active vesicouterine centrifugal fistula. Clin Exp Obstet Gynecol 2001;28:97-9.

4. Holden D, Vere M, Manyonda I. Vesico-uterine fistula occurring in a woman with a previous caesarean section and two subsequent normal vaginal deliveries. Br I Obstet Gynaecol 1994;101:354-6. http:// dx.doi.org/10.1111/i.1471-0528.1994.tb13629.x

5. Miklos JR, Sze E, Parobeck D, et al. Vesicouterine fistula: A rare complication of vaginal birth after cesarean. Obstet Gynecol 1995;86:638-9. http://dx.doi.org/10.1016/0029-7844(95)00135-E

6. Yip SK, Leung TY. Vesicouterine fistula: An updated review. Int Urogynecol J Pelvic Floor Dysfunct 1998;9:252-6. http://dx.doi.org/10.1007/BF01901500

7. Karaltı MO, Tinar S, Öztürk NT, et al. A case with vesicouterine fistula: Mini review. Arch Gynecol Obstet 2012;285:667-70. http://dx.doi.org/10.1007/s00404-011-2188-z

8. Leon Tancer M. Vesicouterine fistula — a review. Obstet Gynecol Surv 1986;41:743-53. http://dx.doi. org/10.1097/00006254-198612000-00001

9. Ikechebelu JI, Ugboaja J0, Okeke (F. Post-Cesarean vesicouterine fistula (Youssef syndrome): report of two cases. J Obstet Gynaecol Res 2011;37:912-5. http://dx.doi.org/10.1111/i.14470756.2010.01428.x

10. Youssef AF. Menouria following lower segment Cesarean section: A syndrome. Am I Obstet Gynecol 1957;73:759-67.

11. Perveen K, Gupta R, Al-Badr A, et al. Robot-assisted laparoscopic repair of rare post-Cesarean section vesicocervical and vesicouterine fistula: A case series of a novel technique. Urology 2012;80:477-82. http://dx.doi.org/10.1016/i.urology.2012.04.027

12. Murphy JM, Lee G, Sharma SD, et al. Vesicouterine fistula: MRI diagnosis. Eur Radiol 1999;9:1876-8. http://dx.doi.org/10.1007/s003300050939

13. Narayanan $P$, Nobbenhuis $M$, Reynolds $K M$, et al. Fistulas in malignant gynecologic disease: etiology, imaging, and management. RadioGraphics 2009;29:1073-83. http://dx.doi.org/10.1148/rg.294085223

14. Brodhead GL. Spontaneous closure of large vesico-uterine fistula. Med Rec 1920;98:437.

15. Rubino SM. Medical treatment of uterovesical fistula. Lancet 1977;1:900. http://dx.doi.org/10.1016/ S0140-6736(77)91218-1

16. Dalela D, Ranjan P, Sankhwar PL, et al. Supratrigonal VVF repair by modified O'Connor's technique: an experience of 26 cases. Eur Urol 2006;49:551-6. http://dx.doi.org/10.1016/j.eururo.2005.12.037

17. Chang-Jackson SR, Acholonu UC, Nezhat FR. Robotic-assisted laparoscopic repair of a vesicouterine fistula. JSLS 2011;15:339-42. http://dx.doi.org/10.4293/108680811X13071180407438

Correspondence: Dr. Funda Gungor Ugurlucan, Istanbul University Istanbul School of Medicine Department of Obstetrics and Gynecology, Turkey; fgungor@yahoo.com 